\title{
PENSANDO O PROCESSO SAÚDE DOENÇA: A QUE RESPONDE O MODELO BIOMÉDICO?*
}

\author{
José Augusto C.Barros**
}

RESUMO: Com o propósito de efetuar uma crítica ao modelo biomédico, mecanicista, hegemônico na doutrina e prática que informa a medicina na atualidade, o texto parte de uma síntese histórico-evolutiva que contempla a apresentaçao das idéias e personagens chave que caracterizariam os quatro paradigmas ou modelos que, ao longo do tempo, precederam o modelo sob estudo. Em seguida discorre, efetuando uma análise crítica, sobre o fenômeno da medicalizaçao, consequência e estímulo ao mesmo tempo para a hegemonia do modelo biomédico, contextualizando-a, brevemente, na sociedade de consumo, sob o império da lógica de mercado, tomando a questao dos medicamentos como exemplo das distorçoes advindas do incremento da medicalização e dos fatores a ela subjacentes. Ao final, comenta-se a respeito das limitações no alcance da desejada interferência positiva da medicina, uma vez feita a opção pelo modelo biomédico.

PALAVRAS-CHAVE: modelo biomédico, processo saúde-doença, medicamentos, medicalização

\footnotetext{
* Apresentado na Mesa Redonda Ciência para a Justiça e Equiidade, em 03/10/01, VII Congresso Paulista de Saúde Pública.

** Professor da Faculdade de Medicina da Universidade Federal de Pernambuco.
} 


\section{MODELOS EXPLICATIVOS DO PROCESSO SAÚDE-DOENÇA:BREVE HISTÓRICO}

$\mathrm{Na}$ trajetória evolutiva das concepções e da prática sobre a saúde e a doença poderiam ser considerados alguns paradigmas que, começando com a visão mágicoreligiosa, na antiguidade, termina na abordagem do modelo biomédico, predominante nos tempos de hoje. Para a elaboração da contextualização de caráter histórico, essencial à reflexão sobre o modelo biomédico aqui pretendida, nos inspiramos, em grande medida, nos textos de Bennet (1981), Capra (1982) e Lain Entralgo (1989).

\section{AS ABORDAGENS DA MEDICINA MÁGICO-RELIGIOSA E DA EMPÍRICO-RACIONAL}

A medicina mágico-religiosa, predominante na antiguidade, se inseria em um contexto religioso-mitológico no qual o adoecer era resultante de transgressões de natureza individual ou coletiva, sendo requerido para reatar o enlace com as divindades, o exercício de rituais que assumiam as mais diversas feições, conforme a cultura local, liderados pelos feiticeiros, sacerdotes ou xamãs. As relações com o mundo natural se baseavam em uma cosmologia que incluíam deuses caprichosos e espíritos tanto bons como maus. Os indivíduos pensavam a doença em termos desses agentes cabendo aos responsáveis pela prática médica da época aplacar essas forças sobrenaturais. Esse enfoque é ainda hoje aceito por milhares de pessoas, habitantes de sociedades tribais ou nao, com a intromissao, concomitante, por vezes, de elementos da medicina ocidental, dita cientifica.

Avanço significativo no pensamento médico ocorre quando se dá um desvio do foco de interesse das forças sobrenaturais para o portador da doença, passando a mesma gradativamente, a ser vista como um fenomeno natural, passível de ser compreendido e liberado da intromissao de forças divinas ou malévolas. Esse novo enfoque, que podería ser designado como medicina empírico-racional teve seus primórdios no Egito (papiros com fragmentos de textos médicos datam de três mil anos antes de Cristo). No ocidente, especulações com vistas a encontrar uma explicação não sobrenatural para a saúde e a doença devem muito aos primeiros esforços de alguns pioneiros em uma forma inédita de aproximação dos fenômenos, na busca do seu entendimento, particularmente na Grécia clássica, iniciando-se no sexto século antes de Cristo, com o nascimento da filosofia (amor à sabedoria) e as tentativas dos primeiros filósofos pré-socráticos em encontrar explicação para as origens do universo e da vida. Essa matéria prima (arké=origem, começo) por eles 
visualizada como sendo a água, a terra, o fogo e o ar, está subjacente à teoria dos humores de Hipócrates (460-377 AC). Pensadas, de início, de forma isolada, acredita-se ter sido Empédocles (490-430 AC) o pioneiro na concepçao do mundo como sendo formado pelo somatório dos quatro elementos que existiriam juntos e em termos iguais, formulando as bases de uma teoria dos elementos que, de alguma forma, estaria presente na medicina ocidental nos próximos dois milênios, teoria que foi aprimorada por outros filósofos atingindo o seu auge à época de Hipócrates, daí em diante persistindo, mais ou menos inalterada, até o século XVI. Associando a bile amarela, bile negra, sangue e fleugma, respectivamente, ao fogo, terra, ar e água, esses humores predominariam em determinada estaçao do ano, isto é, verao (bile amarela), outono (bile negra), primavera (sangue) e inverno (fleugma).

O chamado Pai da Medicina ocidental identificou a saúde como fruto do equilíbrio dos humores, sendo, por oposiçao, a doença, resultante do desequilíbrio dos mesmos. Alguns praticantes da medicina contemporâneos ou sucessores de Hipócrates interpretaram a teoria humoral de maneira mais estrita (abrindo exceçao apenas para os ferimentos), enquanto outros admitiam a intromissao de agentes externos, como os venenos, na determinaçao das doenças. A teoria dos humores sobrevive nos dias de hoje em algumas correntes do pensamento médico oriental, como é o caso, da medicina tradicional tibetana ou da medicina ayuvérdica e unani indianas.

A noção de equilíbrio (crasis, em grego), associa-se à idéia de 'proporção justa ou adequada' e foi desenvolvida de forma mais acabada por Alcmeon, pioneiro na aplicação dessa idéia de equilíbrio nas suas relações com a saúde e a doença. Contemporâneo de Pitágoras, esse filosófo trouxe contribuições marcantes para o que, atualmente, entendese por medicina holística (holos=pleno, integral). Para ele, equilíbrio implicava na interação de duas ou mais forças ou fatores na etiologia das doenças. Alcmeon, de algum modo, reconcilia idéias de Heráclito (540-480 AC) para quem os opostos podem existir em equilíbrio dinâmico ou sucedendo-se uns aos outros, com as de Pitágoras (580-500 AC). Não se visualiza um estado duradouro de harmonia, nem um conflito permanente. É levada, agora, em consideração, não apenas uma mera oposição de duas forças, mas de um conjunto delas, em geral, aos pares, vislumbrando-se a idéia de um sistema no qual atuaria, sobre o indivíduo, simultaneamente, diferentes forças. Na nova concepção, a mistura dos opostos os neutralizariam, produzindo a harmonia, visível, por exemplo, na música ou na saúde. A escola de Alcmeon propugnava, como já o fazia Pitágoras, a existência de uma vida saudável através da meditação, adequação da dieta, moderação em tudo. Surge a concepção de que, tanto quanto o corpo social, o corpo humano requereria um delicado conjunto de 
controles para mantê-lo dentro dos limites apropriados.

Era de se esperar que o pensamento hipocrático, tanto do seu líder, quanto dos seus discípulos, tivesse como pressupostos as contribuições dos filósofos que os antecederam ou dos seus contemporâneos. A escola hipocrática aprofunda estratégias de recuperação da saúde, mas, sobretudo, de prevenção das doenças e que se podem extrair dos fragmentos, reunidos sob a epígrafe corpus hipocraticum nos quais se pode notar a valorização do ambiente de trabalho, da habitação ou da dieta, na determinação do bom estado de saúde.

\section{O GALENISMO}

Partindo dos presupostos hipocráticos é que Galeno (122-199 D.C.), um dos médicos que exerceram maior influência na história da medicina ocidental, fará avanços significativos nas concepções diagnóstico-terapêuticas tendo as mesmas predominado durante nada menos que 14 séculos, isto é, por quase toda a idade média. Pesquisador clínico e escritor notável, suas idéias, inspiradas, de início na escola de Hipócrates e seus sucessores, alcançaram, para a época, uma profundidade e repercussões notáveis. Anatomista, fisiólogo e terapeuta, Galeno realiza uma síntese do conhecimento médico existente fazendo-o avançar no contexto do Império Romano e da expansão do cristianismo. A idéia central de sua visão da fisiologia repousa no fluxo permanente dos humores, o que estaria na dependência das influências ambientais, do calor inato e, em grande medida, da ingesta alimentar e sua justa proporção. As causas mórbidas podiam ser internas (ligadas à constituição e predisposição individual), externas (excessos alimentares, sexuais ou de exercícios físicos) ou conjuntas. O diagnóstico deve ter por fundamentos o cuidadoso exame do doente, o conhecimento do seu estado quando sadio, seu temperamento, regime de vida, alimentação, além das condições ambientais e a época do ano. Vale ressaltar, no caso da terapêutica, a importância outorgada por Galeno, à natureza (vis medicatrix naturae). Extremamente válidas - e contemporâneas - são suas referências ao potencial curativo, mas também, venenoso, dos medicamentos. Para ele, deveria ser outorgada maior ênfase ao uso dos medicamentos fitoterápicos, considerando o fato de que os de origem mineral seriam mais tóxicos e os de origem animal, mais débeis.

O enfoque galênico floresceu no contexto da hegemonia da filosofia escolástica elaborada, sobretudo, por Tomás de Aquino, igualmente renomado pela sua condição de 
teólogo. Segundo o tomismo, o raciocínio lógico se constituía em uma forma de se chegar à verdade superior à representada pela observação empírica. Apesar de não se poder negar que a escola galênica forneceu as bases para a prática médica hegemônica na Europa, terminou por erigir-se em um dogma, ficando impermeável à incorporação das descobertas surgidas nos séculos XV e XVI.

\section{A CONTRIBUIÇAO DE PARACELSO}

Paracelso (1493-1541) representa um modelo de transição entre a escola galênica e o modelo biomédico. Segundo ele havia uma ordem determinada que organizava o micro e o macrocosmo, ambos governados por um princípio vital por ele denominado de archeus. Influenciado pela alquimia visualizava uma composição mineral na matéria, inclusive na orgânica, chamando a atenção para as semelhanças existentes entre os processos químicos e os processos vitais. Na determinação da doença, Paracelso identificava influências cósmicas e telúricas além de substâncias tóxicas e venenosas, bem como da predisposição do próprio organismo e das motivações psíquicas. A doença também se explicava em virtude de reações inadequadas dos elementos constitutivos do mundo (excesso de um ou de mais de um deles). Uma, entre as múltiplas orientações de Paracelso para uma correta prática médica, proclamava: A prática desta arte repousa no coração; se o teu coração é falso, o mesmo se dará com o médico que está dentro de ti. Onde não existe amor, não existe arte; portanto, o médico não deve estar imbuído de menos compaixão e amor do que os que Deus direciona aos homens.

Autor de um conjunto de idéias que formavam um sistema médico complexo, sincrético (reunindo a alquimia, medicina popular, astrologia, a tradição renascentista e sua peculiar visao crista do mundo), Paracelso se opunha vivamente às ideías do passado (em especial à teoria dos humores e ao pensameno galênico). Dotado de um temperamento excêntrico, passional, esteve no cerne de contendas com seus colegas, sobretudo ao propugnar o caráter de entidade independente para a doença a qual necessitaria ser tratada com remédios específicos, com frequência, de origem química. Entre as suas contribuições terapêuticas podem ser citadas: o tratamento conservador das feridas e úlceras crônicas, baseado na sua crença no poder curativo da própria natureza; a introdução do laudanum (tintura de ópio); a utilização de compostos de mercúrio no tratamento da sífilis; o reconhecimento do bócio e do cretinismo como decorrência de deficiências minerais; a 
identificação de problemas, hoje diagnosticados como silicose e tuberculose, que representariam riscos ocupacionais para os que trabalhavam em minas.

A influência de Paracelso cresceu após sua morte e muitos dos seus admiradores se destacaram no exercício de uma prática médica afastada da convencional, ainda que atentos às inovações. Quase um século depois, o médico londrinense Robert Fludd (15741629) estabeleceu uma espécie de ponte entre Paracelso e as novas correntes filosóficas dos séculos XVI e XVII (em especial, as chamadas "filosofias químicas" cujos adeptos propugnavam a compreensão da natureza através da análise química, o que, no âmbito da medicina, incluía uma oposição às idéias de Galeno, com duas correntes principais: uma, seguidora da tradição de Paracelso, com sua visão holística e mística do mundo; a outra, mais prática e macanicista, preocupando-se menos com a essência das coisas e mais com sua forma e movimento (Bennet, 1987). Fludd era adepto dos novos agentes químicos na terapêutica e sua oposição a Galeno fez com que sua entrada no College of Physicians ocorresse apenas à quinta tentativa.

\section{O MODELO BIOMÉDICO}

O modelo biomédico ou mecanicista, hoje predominante, tem suas raízes históricas vinculadas ao contexto do Renascimento e de toda a revolução artístico-cultural que ocorre nessa época, associada, igualmente, ao projeto expansionista das duas metrópoles de então - Portugal e Espanha - cuja consecução vai demandar o surgimento de instrumentos técnicos que viabilizem as grandes navegações (astrolábio, bússolas, caravelas, avanços na cartografia, etc.), na tentativa, como se sabe, entre os fatores que prioritariamente estimularam o mencionado empreendimento, de reatar o intercâmbio comercial com as Indias, coarctado a partir da tomada de Constantinopla pelos turcos, em 1453.

Como precursores significativos das mudanças radicais de ordem técnico-científica ocorridas a partir do século XV hão de ser citadas as contribuições dos astrônomos, particularmente Copérnico e Galileu e, mais adiante, Kepler. A teoria geocêntrica ptolomaica, até então hegemônica e inquestionável, é substituida pela heliocêntrica, a despeito da força dos dogmas católicos proclamados como única forma aceitável de visualizar o universo e todo e qualquer fenômeno, ficando sob risco de enquadramento nos rigores da inquisição aqueles que deles discordassem (e a história dos tribunais da inquiçao evidenciam quão 
longe se chegou nesse propósito de reprimir os chamados anátemas e hereges que abraçavam idéias nao ortodóxas).

O filósofo e matemático René Descartes (1596-1650) é o responsável por um método e uma escola filosófica pioneira na habilitação privilegiada do sujeito que conhece (res cogitans) frente ao objeto ou realidade externa a ele e que vai ser conhecida (res extensa). No seu Discurso do Método Descartes fórmula as regras que se constituem os fundamentos de seu novo enfoque sobre o conhecimento e que persistem hegemônicos no raciocínio médico ainda hoje. A primeira regra preceitua que nao se deve aceitar como verdade nada que não possa ser identificado como tal, com toda evidência, isto é, hão de ser, cuidadosamente evitados a precipitação e os preconceitos não ocupando o julgamento com nada que não se apresente tão clara e distintamente à razão que não haja lugar para nenhuma dúvida. A segunda regra propunha separar cada dificuldade a ser examinada em tantas partes quanto sejam possíveis e que sejam requeridas para solucioná-la. A terceira dizia respeito à condução do pensamento de forma ordenada, partindo do mais simples e fácil daí ascendendo, aos poucos, para o conhecimento do mais complexo, mesmo supondo uma ordem em que não houvesse precedência natural entre os objetos de conhecimento. $A$ última regra se referia à necessidade de efetuar uma revisão exaustiva dos diversos componentes de um argumento de tal maneira que seja possível certificar-se de que nada foi omitido (Descartes, 1960). Uma preocupação adicional de Descartes residia na certeza a que ele podia chegar por meio de provas matemáticas.

A Isaac Newton coube a criaçao de teorias matemáticas que confirmaram a visão cartesiana do corpo e do mundo como uma grande maquina a serem explorados. Assim como a mecânica newtoniana possibilitou a explicaçao de muitos fenomenos da vida cotidiana, a medicina mecanicista passa a fornecer, gradativamente, os intrumentos requeridos pelos médicos para que pudessem lidar de forma cada vez mais satisfatória, com uma parte crescente das doenças mais corriqueiras. Nao podem ser negados - tanto quanto seria descabido fazê-lo nos dias de hoje - os notáveis avanços ocorridos no campo das ciências biológicas, a partir do século XVII, à medida que também evoluiam a física e a química. O que, cabe, sim, continuar questionando são os descaminhos ou as estratégias e interesses que, em especial a partir da revolução industrial capitalista passaram a prevalescer e que mais adiante serão objeto de maiores considerações.

Agora, o alvo do interesse médico passou da história da doença para uma descrição clínica dos achados propiciados pela patologia, isto é, como diz Bennet (1987), de uma 
abordagem biográfica para uma outra, nosográfica. Grande parte das descobertas da medicina moderna foram sendo, paulatinamente, validadas pela abordagem biomédica. Alguns exemplos, entre tantos, dessas descobertas podem ser realçados, tais como os estudos anatômicos de Vesalius (publicados em 1543), a descoberta da circulação sanguínea por William Harvey, em 1628 e da primeira vacina por Edward Jenner (1790-1823). Mais adiante, na década de 1860 e subsequentes, a era bacteriológica se instaura com a decisiva participação, com merecido destaque, entre outros, de Louis Pasteur e Robert Koch, o primeiro evidenciando o papel das bactérias, seja no processo de fermentação, seja nas doenças, além de, entre outras contribuiçães, ter chegado às vacinas anti-rábica e contra o Anthrax e o segundo, tendo descoberto o agente etiológico da tuberculose e formulado os postulados que tipificam o rigor do raciocínio mecanicista e sua insistência na correlação causa-efeito: o microorganismo está presente e pode ser detectado em todo caso da doença; ele pode ser cultivado em meio de cultura apropriado; a inoculação desta cultura reproduz a doença em animal susceptível e o microorganismo pode ser recuperado, de novo, do animal infectado.

A teoria microbiana passa a ter, já nos fins do século XIX uma predominância de tal ordem que, em boa medida, faz obscurecer concepções que destacavam a multicausalidade das doenças ou que proclamavam a decisiva participação, na eclosão das mesmas dos fatores de ordem socioeconômica.

No campo da epidemiologia, o trabalho precursor de John Snow abriu caminho para a compreensão dos elos presentes na determinação das doenças pestilenciais ou epidêmicas e para a possibilidade de intervir sobre as mesmas. Obviamente, no que concerne à abrangência das doutrinas que tentavam compreender o processo saúde-doença, buscando entender a complexidade da sua determinação, já se chegara, no século XVIII, a enormes avanços. Veja-se a respeito os trabalhos de Rosen (1980; 1997), Sigerist (1961), Singer (1981), Foucault (1993), entre tantos outros.

As descobertas mencionadas e tantas outras requeriam um modelo explicativo que pudesse incorporar as inovadoras concepções sobre a estrutura e funcionamento do corpo. Durante largo período de tempo, médicos e pacientes tiveram sua atenção voltada para o todo e a interação harmônica das partes. O novo modelo explicaivo introduz a gradativa reorientação nos princípios e práticas que irão conformar a nova medicina, sendo mui ilustrativo o modelo mecânico que se erige como analogia para a compreensao do funcionamento do corpo: o relógio e suas engrenagens. Vale a pena, nesse contexto, realçar 
o fato de que, tanto quanto o próprio Descartes, tido como o pai do racionalismo na moderna filosofia, aos cientistas, de maneira geral, nos séculos XVI e XVII, nao parecia difícil ou incongruente conciliar a crença religiosa com suas observações empíricas. Contudo, o empirismo (na formulação de suas bases, não se pode esquecer a contribuição decisiva de Francis Bacon, o primeiro a formular os fundamentos do método indutivo) foi, aos poucos, tal como ressalta Bennet (1987), substituindo a especulação como fonte primordial da descoberta da verdade e dos segredos da natureza, o que pode ser observado com mais clareza, seja na astronomia, onde as antigas cosmologias, a despeito das reações eclesiásticas, deram lugar a novas teorias, seja na física, com Newton (teoria da gravitação universal, unificação das diversas explicações sobre a natureza e propagação da luz e tantas outras importantes contribuições). Bennet (1987), em todo caso, chama a atenção para não se exagerar no grau de culpabilidade imputado a Descartes e Newton pelos críticos da medicina mecanicista contemporânea. Para Bennet, suas concepções estariam bem distantes daquelas dos iatromecanicistas de hoje, cujo precursor máximo seria Julien Offray de la Mettrie (1709-1751) para quem mesmo as doenças mentais teriam uma origem física, a propósito, uma perspectiva de todo coerente com muito do que se partica e investiga na psiquiatria contemporânea (uma apreciação crítica das doutrinas, sobretudo relacionadas às terapêuticas que elas propugnam, de escolas médicas dominantes na Europa e no Brasil nos dois últimos séculos, foi feita por Sayd (1999).

Se quisermos ilustrar ainda mais - e com exemplos mais ou menos recentes - o raciocínio mecanicista, podemos tomar o caso do diabetes. Em 1889, se descobre que a alteração metabólica, essência dessa enfermidade, podia ser reproduzida removendo-se o pâncreas, em 1921 detectando-se que a administração de insulina aliviava os sintomas. Estava-se diante de mais um clara demonstração de como uma deficiência na "máquina" provocava doença que podia ser "curada" através do emprego de uma substância específica. Sucessos ainda mais impressionantes proviriam das descobertas da imunologia, elucidação da estrutura do DNA, e, mais recentemente, do mapeamento do genoma humano e das conquistas da engenharia genética. A adesão massiva ao raciocínio e práticas biomédicas tem a ver com as supostas soluções - muitas vezes, em realidade, meramente paliativas por não agirem nas causas propriamente ditas - precisamente por se concentrarem nas 'partes' de um sistema ou de um processo que, na sua essência, são bem mais complexos.

Tanto quanto nas ciências biomédicas, o êxito do paradigma mecanicista, em termos das leis gerais que tentavam explicar os fenômenos da natureza, fez com o mesmo se tornasse hegemônico por quase 14 séculos. A nova concepçao, como ressalta Capra (1986) 
colocou em evidência a índole mecânica dos fenômenos celestes e terrestres e, logo, dos seres vivos, podendo-se considerar que a noção de um universo orgânico e espiritual, com o qual o homem entretia relações harmônicas, é substituída pela de um mundo que passa a ser tido como uma máquina, convertida na metáfora dominante da era moderna. 0 paradigma mecanicista só veio a sofrer algum questionamento quando outras teorias se fizeram necessárias para dar conta da explicação, em especial nos campos da física e da química, de determinados fenômenos. Tais são os casos, à guisa de exemplos, do eletromagnetismo, para o que foram importantes as contribuições de Faraday e Maxwell, ou das teorias quântica (Max Plank), da relatividade (Einstein) ou da Evolução (Jean B.Lamarck e Charles Darwin).

\section{O FENÔMENO DA MEDICALIZAÇÃO}

É provável que a expressão mais acabada das distorções e consequências concretas do modelo biomédico, reducionista, de abordagem da saúde e da doença na vida dos indivíduos resida no que se convencionou designar como medicalização.

Ivan Illich, por meio do seu livro Némesis medicale, l' expropriation de la santé, publicado em meados dos anos setenta, foi um dos pioneiros em apontar os descaminhos da moderna medicina e sua sofisticação tecnológica. Seu texto suscitou profícuo debate e, apesar de eventuais equívocos, contribuiu para evidenciar as distorções do 'complexo médico industrial' e a necessidade de redirecionamento na forma como estavam sendo estruturados os serviços de saúde. Navarro, em 1975, mesmo ano da publicação do texto de Illich, em crítica a algums das teses do mencionado autor, chama a atenção para o fato de que a industrialização e seus reflexos no campo da medicina, sao apresentados como causa dos prejuizos à vida dos indivíduos e não como um elo no contexto mais geral do sistema capitalista de produção e consumo (Navarro, 1975).

Inúmeros estudos têm sido feitos a respeito da sociedade de consumo, da ideologia que o incentiva e da vinculaçao crescente do mesmo ao bem-estar e à felicidade. Uma bem elaborada e acessível síntese das relações entre produção e consumo, no contexto do capitalismo, sob a ótica do materialismo dialético, foi feita por Giovanni (1980).

Na medida em que o acesso ao consumo foi convertido no objetivo principal para o desfrute de níveis satisfatórios de bem-estar, bons níveis de saúde passaram a ser vistos 
como possíveis na estreita dependência do acesso a tecnologias disgnóstico-terapêuticas. A eficácia e efetividade das mesmas passam a confundir-se com seu grau de sofisticação. Como decorrência inevitável do aprofundamento no conhecimento dos pedaços do organismo, aparecem as super e subespecializações desbancando o antigo clínico geral (de alguma forma ressuscitado, na atualidade, com os médicos de família, tradicionais em países como Cuba e, agora, presentes nos Programas de Saúde da Família, institucionalizados pelo Ministério da Saúde). Os fenômenos referidos foram sendo instaurados ao longo da evolução ténico-científica por que vão passando as ciências biomédicas, antes comentada, e se intensificam no último século, consolidando o modelo biomédico e, como parte dele, a medicalização. Esta pode ser entendida como a crescente e elevada dependência dos indivíduos e da sociedade para com a oferta de serviços e bens de ordem médico-assistencial e seu consumo cada vez mais intensivo (Barros, 1984). Essa intromissão desmesurada da tecnologia médica passa a considerar como doença problemas os mais diversos (situações fisiológicas, problemas cuja determinação são, em última análise, fundamentalmente, de natureza econômico-social), como tal demandando, para sua solução, procedimentos médicos. Não importa que - ou quiçá, é isto que interessa - em muitos casos, os resultados obtidos constituam meros paliativos ou até mesmo sirvam à manutenção do status quo. O manejo da gravidez e do parto como se fosse uma "doença" e, por isto mesmo, requerendo atenção permanente do aparato médico, é um bom exemplo de algo fisiológico que é 'medicalizado', bastando citar, para confirmar a assertiva, a multiplicação dos partos cesareanos, sem justificativa técnica ou a monitorização sistemática da gravidez pela ultrasonografia, mesmo em grávidas sem nenhuma história pregressa ou atual que possam vir a ser tidas como 'risco'. A redução, objetivamente mensurável, da mortalidade perinatal e materna é atribuída, em caráter exclusivo, ao moderno acompanhamento médico possível pela aplicação de inovações tecnológicas. É omitida a contribuição crucial, no descenso dos coeficientes mencionados, da melhoria nutricional, melhor distribuição dos serviços obstétricos básicos, redução da quantidade de certas categorias de gravidez de alto risco (Taylor, 1979).

Paralelamente às influências do mecanicismo e a extrapolação de seu raciocínio do mundo físico, do universo, para o mundo dos seres vivos, a medicalização sofre o impacto, a partir da revolução industrial que instaura o capitalismo, da transformação de tudo em mercadoria, em princípio destinada a produzir lucros. Está aberto o campo para a gestação do 'complexo-médico-industrial' e para a mais ampla possível mercantilização da medicina, com todos os malefícios daí decorrentes, especialmente no acesso nao equânime e universal aos serviços médico-assistenciais, inclusive aos essenciais e o que é mais grave, ainda, 
nas sociedades, como a nossa, marcada por cruel concentração da renda e, daí, de todos os bens e serviços. Ultrapassa os objetivos do presente texto, a análise das estratégias eventualmente adotadas por indivíduos ou por organizações da sociedade civil (como os movimentos de defesa do consumidor, do desenvolvimento sustentável ou do meio ambiente) em favor de uma reorientação do modelo econômico fundado no neoliberalismo, hoje dominante em inúmeros países e, nesse contexto, do modelo médico-assistencial (mais direcionadas à problemática dos medicamentos, tecemos considerações sobre o tema, na reedição, no prelo, de texto de nossa autoria (Barros, 1995)

Selecionar o medicamento, ainda que análises de teor similar pudessem ser, também, feitas em relação aos exames laboratoriais, e o papel que, sobretudo a partir de sua quimiosíntese industrial, ele passou a desempenhar no seio do sistema sanitário e na prática de consumidores e prescritores, poderá ilustrar sobremaneira, seja a medicalização, seja a perspectiva reducionista e os interesses a que serve o modelo biomédico. Diversos autores têm se ocupado, no Brasil, do tema, em muitos casos aprofundando um ou outro aspecto da complexa cadeia que vai da produção ao consumo dos medicamentos (Giovanni,1980; Cordeiro, 1985; Temporao, 1986; Bermudez, 1995; Carline, 1995; Barros, 1995).

O papel extratécnico dos medicamentos diz respeito à extrapolaçao de sua ação farmacológica, associada ao 'valor-de-uso', para usar uma categoria marxista e que ultrapassa, igualmente, o seu 'valor-de-troca' (caráter de mercadoria de um bem qualquer, utilizando o mesmo referencial teórico). A lógica de mercado, atuante desde os primórdios da indústria farmacêutica moderna, estimula, intensivamente a extrapolação mencionada, agindo suas técnicas promocionais, com grande vigor, em uma outra dimensão, que poderia ser designada como 'valor simbólico'. Sobre médico e paciente paira uma representação do processo saúde-doença e das estratégias para manejá-las que, de alguma maneira, inclui um caráter mágico, sendo este último pensado como o desejo de agir sobre algo, exercendo um domínio sobre ele ou sobre um de seus signos. Ao tomar um medicamento o que se quer é que o mesmo interfira sobre os sintomas ou sinais da doença (signo da fragilidade humana), sob a ilusão, mesmo que, aparentemente respaldada nos pressuspostos técnico-científicos os mais sólidos, de se está atuando sobre eles e, na medida do possível, dominando-os. Em uma sociedade em que, para quaisquer problemas, busca-se um 'remédio' oferecido pela ciência, os antigos instrumentos de dominação mágica do mundo foram substituídos por objetos técnicos. Tal como ressalta Dupuy \& Karsenty (1980), em virtude das funções atribuídas aos fármacos, a expectativa é de que os mesmos tragam 
algum conforto moral, diminuam a sensação de insegurança, aliviem a angústia, preencham vazios, em suma, ajudem a viver.

Ao fazer uma análise do fenômeno da reificação e simbolização do fenômeno da saúde, dando ênfase à sua concretização através do medicamento, Lèfevre (1991), expõe mui apropriadamente, ao nosso ver, as relações no plano simbólico que médico e paciente entretêm com o mencionado produto. Até o século XVIII, o medicamento representava muito mais um recurso adicional disponibilizado aos médicos. Com o decorrer do tempo e, sobretudo, quando os produtos farmacêuticos passaram a requerer uma prescrição médica, a dimensão simbólica se intensifica mais ainda, tendo outras concepções assumido a condição de irracionais ou supersticiosas. A dimensão simbólica referida vai servir, igualmente, para escamotear o viés econômico que não se coaduna ao caráter sagrado, secerdotal, inerente ao profissional que atua como agente da cura (como tal, a prescrição se justifica em função da vida e da saúde, nao sendo cabível especulações sobre gastos) (Comelles, 1993). Os múltiplos aspectos socioculturais e comportamentais envolvidos na questão dos medicamentos têm sido objeto de diversos ramos das ciências sociais e sua aplicação à área da saúde, como é o caso da antropologia médica, sendo uma referência oportuna, com respeito, especificamente, aos medicamentos, a revisão feita por Nichter \& Vuckovic (1994).

\section{LIMITAÇÕES DO MODELO BIOMÉDICO}

Paralelamente ao avanço e sofisticação da biomedicina foi sendo detectada sua impossibilidade de oferecer respostas conclusivas ou satisfatórias para muitos problemas ou, sobretudo, para os componentes psicológicos ou subjetivos que acompanham, em grau maior ou menor, qualquer doença. As críticas à prática médica habitual e o incremento na busca de estratégias terapêuticas estimulada pelos anseios de encontrar outras formas de lidar com a saúde e a doença (no seu conjunto designadas como medicinas alternativas ou complementares) constituem uma evidência dos reais limites da tecnologia médica. Mesmo que muitos profissionais cheguem a admitir a existência de componentes de ordem subjetiva ou afetiva que exercem influência mesmo em casos de doenças em que as evidências orgânicas sejam mais explícitas, não se sentem, com frequência, à vontade para lidar com os mesmos, pois para isto, via de regra, não foram preparados. De fato, o modelo biomédico estimula os médicos a aderir a um comportamento extremamente cartesaino na separação 
entre o observador e o objeto observado. Proclama-se a necessidade de um 'distanciamento objetivo', visto como uma qualidade que cabe preservar ou mesmo incrementar, por mais que seja inerente ao ato médico uma interação inescapável e mais ou menos intensa entre médico e paciente e que esta interação seja fundamental para o sucesso terapêutico. A intensificação da divisão do indivíduo em pedaços contribui sobremaneira para dificultar a valorização do todo. Até mesmo se nos restringirmos ao âmbito terminológico, os médicos ocidentais têm dificuldades em descrever o todo, a não ser por meio das partes. Desta maneira, por mais que alguns profissionais queiram visualizar seu paciente como um todo $e$ situá-lo, de alguma maneira, no seu contexto socioeconômico, terminam por regressar ao reducionismo, pois este foi o modelo em que foi pautada sua formaçao na escola médica. Tudo o que acontece aos pacientes, quaisquer das suas queixas ou sofrimentos são vistos - e, como decorrência, manejados - em termos mecanicistas, isto é, tenta-se "patologizar" (Taylor (1979) criou o neologismo diseasefication, ao nosso ver muito apropriado) e enquadrar tudo nos cânones da biomedicina (oxalá não seja esquecida a existência dos desviospadrao!...). Um paciente que, hospitalizado e prestes a submeter-se a uma cirurgia, por ventura comenta suas preocupações com algum membro do corpo médico, rapidamente se Ihe diagnostica um estado ansioso, merecedor da prescrição de um tranquilizante. A própria morte, termo inevitável da vida, passou a ser vista como um reflexo da incapacidade do médico ou dos sistemas responsáveis pela manutenção da vida. Apreciação crítica muito pertinente sobre os limites objetivos da medicina frente à morte foi feita pelo filósofo françês contemporâneo, André Comte Sponville, em capítulo de um de seus livros, mui apropriadamente denominado Morrer curado (Sponville, 2000). É interessante, ainda, ressaltar, quão flexíveis são as correntes de pensamento antigas para incorparar, quando preciso, princípios e técnicas da medicina ocidental moderna, haja visto o exemplo dos médicos chineses de hoje, em cuja formação se incluem, mesmo com ênfase na escola médica específica, conhecimentos tanto da medicina tradicional, quanto da ocidental moderna.

Um problema adicional significativo diz respeito aos custos envolvidos nas novas tecnologias médicas para cujo enfrentamento os indivíduos ou o serviço público de saúde se sentem cada vez mais impotentes. Tal como já comentado antes, a lógica de mercado e os interesses envolvidos quando tudo foi transformado em mercadoria desempenha um papel extremamente importante nessa ampliação de gastos, na medida em que tudo é feito sob a égide da ânsia pela ampliação sem limites dos lucros, muitas vezes com pouco ou nenhum controle por parte do Estado ou de outros instrumentos que atuem em defesa dos interesses dos usuários dos serviços de saúde. 
Em fim, fazendo nossas as considerações de Bennet, o que as escolas médicas do passado - seja a antiga medicina grega, sejam, as ainda em vigor, concepções da medicina ayuvérdica ou unani - têm a ensinar ao médico ocidental, sempre cético em tudo que não se fundamente na anatomia, fisiologia e patologia modernas, é, sobretudo, a visão integral do paciente. Não se faz mister quaisquer subsídios, entre nós, para entender as partes. $\mathrm{O}$ que, sim, se faz necessário é a compreensão do todo e de como as partes interagem. Urge visualizar o indivíduo (o que significa, etimologicamente, 'indivisível') como único devendose, pois, considerar menos, se determinado tratamento funciona, pensando na maioria dos pacientes, mas se o mesmo funcionará para este paciente em particular, com estes problemas pessoais, neste tempo de sua vida, neste ambiente, neste recanto do país e do mundo, etc. Em outras palavras, o enfoque primordial não deve continuar se concentrando naquilo que o paciente tem em comum com outros, mas nas suas peculiaridades.

O problema central do modelo biomédico não reside em uma espécie de maldade intrínseca que o caracterizaria, mas no fato de que ele é demasiado restrito no seu poder explicativo, o que implica em óbices importantes para a prática de médicos e pacientes. Tal como ressalta Bennet (1987), médicos sensíveis estão insatisfeitos com o referido modelo, não propriamente porque o mesmo não responde a muitos dos problemas clínicos e sim, devido ao fato de que se dao conta das reações psicológicas dos seus pacientes e dos problemas socioeconômicos envolvidos na doença, mas não vêem como incorporar essas informações na formulação diagnóstica e no programa terapêutico. Nas concepções orientais - caso de medicina chinesa e sua teoria do yin-yang - o enfoque é substancialmente qualitativo e as explicações que hão de ser dadas, asumem a forma de valores. No ocidente há uma tendência ao privilegiamento das explicações de natureza quantitativa, reduzindo-se, com freqüência a 'qualidade' à expressão numérica, estatística, da mesma, quando esta última, ainda que de grande utilidade, nos fornece uma 'probabilidade' ou uma resposta em termos de 'médias'.

No que respeita aos medicamentos, ao hipervalorizar as funções que os mesmos podem vir a desempenhar, além da geração de uma dependência pela qual se crê que, para todo e qualquer problema, independentemente de sua gravidade ou nexos causais, haverá uma pílula salvadora, deparamo-nos com um incremento nos custos, tanto econômicos, quanto, propriamente, sanitários. Essa verdadeira "cultura da pílula", identifica bons níveis de saúde, com alto grau de consumo. Prescritos ou não por médicos - já que, em nosso país, os balconistas de farmácia também atuam como prescritores (Barros, 1997) - ou consumidos através da automedicação, a expectativa criada é sempre favorável, em relação 
às novidades, continuamente, lançadas no mercado pela indústria ou prometidas para logo mais, desconsiderando-se por um lado que, muitas das supostas novidades, na realidade não o são (Barros, 1996) e, sobretudo, que um padrão de saúde adequado, menos que fármacos, com mais freqüência, requer mudanças sociais ou comportamentais ou, no caso do Estado, menos gastos com compra de medicamentos e mais com saneamento básico, educação ou melhoria nas oportunidades de emprego e de distribuição da renda. O referencial mecanicista, reforçando explicações que reduzem o processo saúde-doença à sua dimensão estritamente biológica, propaga, inclusive pela mídia ou pelos sites da internet, tanto as "soluções" que já vieram à luz como as que estão prestes a fazê-lo (produtos para impotência, novos antireumáticos e antidepressivos, fármacos para enxaqueca, osteoporose, obesidade ou para abandonar o hábito de fumar).

O uso mais adequado dos medicamentos, ao lado de controles mais estritos sobre o registro de novos produtos, implementação de um sistema de farmacovigilância, indispensável ao acompanhamento das reações adversas que surgem pós-comercialização, implica, entre outras estratégias, na disponibilidade de informações isentas do viés mercadológico, tanto para prescritores, como para consumidores. Já está mais do que provado que os produtores de medicamentos investem intensivamente em atividades promocionais (sobre as quais, aliás, urge impor regras que defendam os interesses da coletividade), tendo, inclusive, um duplo padrão de conduta, segundo o país onde disseminam seus produtos e as informaçoes veiculadas sobre os mesmos (Schulte-Sasse, 1988; US Congress OTA, 1993; Barros, 2000).

\section{REFERÊNCIAS BIBLIOGRÁFICAS}

BARROS, J.A.C. Medicalización y salud. Cuad.med.soc. 28:25-31, 1984.

BARROS, J.A.C. Propaganda de medicamentos: Atentado à saúde? São Paulo, HucitecSobravime, $1995,222 \mathrm{p}$ ( $2^{\mathrm{a}}$ ediçao no prelo)

BARROS, J.A.C. A multiplicação de especialidades no mercado farmacéutico: instrumento a serviço da saúde? Saúde em debate, 51:59-63, 1996.

BARROS, J.A.C. A atuaçao dos balconistas de farmácia: ajudando a promover saúde? JBM, 73(2):120-7, 1997.

BARROS, J.A.C. A (des)informação sobre medicamentos: o duplo padrão de conduta da indústria farmacéutica. Cadernos Saúde Pública, 16(2):110-119, 2000. 
BENNET, G. The wound and the doctor: healing, technology and power in modern medicine. London, Martin Secker and Warburg, 1987, 313 p.

BERMUDEZ, J.A.Z. Indústria farmacéutica, estado e sociedade. São Paulo, HucitecSobravime, 1995.

CAPRA, F. O ponto de mutação. São Paulo, Cultrix, 1982.

CARLINE, E.A. Medicamentos, drogas e saúde. São Paulo, Hucitec-Sobravime, 1995, 225 p.

COMMELES, J.M. La utopia de la atención integral en salud. Automedicación, práctica médica y asistencia primaria. Revisiones de Salud Pública (3):169-192, 1993.

CORDEIRO, H. A indústria da saúde no Brasil, $2^{a}$ edição, Rio de Janeiro, Graal-Cebes, 1985.

DESCARTES, R. Discourse on Method. London, Harmonds-worth-Penguin, 1960.

DUPUY, J.P. \& KARSENTY, S. A invasão farmacêutica, Rio de Janeiro, Graal, 1980.

FOUCAULT, M. Microfísica do poder, Rio de Janeiro, Graal, 1993.

GIOVANNI, G. A questão dos remédios no Brasil - produção e consumo, São Paulo, Polis, 1980.

ILICH, I. A expropiação da saúde: nêmesis da medicina, Rio de Janeiro, Nova Fronteira, 1975.

LAIN ENTRALGO, P. Historia de la Medicina, Barcelona, Salvat, 1989.

LEFÈVRE, F. O medicamento como mercadoria simbólica, São Paulo, Cortez, 1991.

NAVARRO, V. La industrialización del fetichismo o el fetichismo de la industrialización - a propósito de nemesis médica. Barcelona, Anagrama, 1975.

NICHTER, M. \& VUCKOVIC, N. Agenda for an anthropology of pharmaceutical practice, Soc.Sci.Med. 39(11)509-525, 1994.

ROSEN, G. Da polícia médica à medicina social - ensaios sobre a história da assistência médica, Rio de Janeiro, Graal, 1980.

ROSEN, G. Uma história da saúde pública, São Paulo-Rio de Janeiro, Ed.Unesp/Hucitec/ Abrasco, 1997.

SAYD, J.D. Mediar, medicar, remediar, Rio de Janeiro, Editora da UERJ, 1999.

SIGERIST, H.E. A history of Medicine, Vol.2, New York, Oxford University Press, 1961. 
SINGER, P. et al. Prevenir e curar - o controle social através dos serviços de saúde. Rio de Janeiro, Forense-universitária, 1981.

SPONVILLE, A.C. Morrer curado? in Bom dia, angústia, Sao Paulo, Martins Fontes, 2000, p.59-75.

SCHULTE-SASSE, H. \& HARTOG, R. La industria farmacéutica alemana en America Latina. Bielefeld, Buko Pharma-Kampagne, 1988.

TAYLOR, R. Medicine out of control - the anatomy of a malignant techonology. Melbourne, Sunbooks, 1979.

TEMPORÃO, J.G. A propaganda de medicamentos e o mito da saúde, Rio de Janeiro, Graal, 1986.

US CONGRESS, OTA (Office of technology assessement). Drug labeling in developing countries, OTA-H-464, Washington DC, Government Printing Office, 1993.

\title{
CONSIDERING THE HEALTH-DIESEASE PROCESS: WHAT DOES THE BIOMEDICAL MODEL ANSWER TO?
}

\begin{abstract}
Aiming at expressing criticism to the biomedical model, which is mechanicist and hegemonic in the doctrine and practice that currently provide information to Medicine, the text starts from a historic-evolutive synthesis, presenting ideas and key-characters that were typical of the four paradigms or models that came before the model under study. Later, in a critical analysis, the paper describes the phenomenon of medicalization, a simultaneous consequence of and stimulus to hegemony of the biomedical model. Such hegemony is briefly put in context in consumption society, under the empire of market logic, and taking the issue of medicines as an example of distortions created by increased medicalization and its underlying factors. Finally, he comments on limitations to achieve the desired positive interference of Medicine, once the option for the biomedical model is made.
\end{abstract}

KEYWORDS: biomedical model; health-disease process; medicines; medicalization 